\title{
SALT POISONING IN PIGS AND POULTRY.
}

By Capt. J. T. EDwARDS, B.Sc., Senior Research Assistant, Pathological Department, Royal Veterinary College, London.

CASES of alleged salt poisoning among the domesticated animals. are not rare, but it is with reference more particularly to the pig. that the subject has been assumed to have most considerable importance. The greater number of the published records deal with poisoning in that animal, and the toxic dose for it has been. represented as from 4 to 8 ozs. Lander, however, failed to observe any abnormal effects in a pig that was fed with six daily 3-oz. doses of salt, and in his standard work on veterinary toxicology he says: "Arising no doubt from the general acceptance of salt poisoning as liable to affect pigs, there is a widespread idea that household waste liquors of all sorts may kill these animals. In a very large number of alleged salt or soda cases analysis of the stomach contents. fails to reveal an excess either of sodium chloride or of carbonate. It is not possible to state the doses of salt necessary to kill the pig, and some recorded examples are not free from doubt; thus it is not unlikely that brines may contain organic poisons derived from the decomposition of proteins; and in salted potato cases there is the possibility of poisoning by the alkaloid solanine contained in diseased potato. Nor is the mechanism of salt poisoning well understood, for, apart from the gastric disturbances naturally to be anticipated, there appear to be definite nervous effects. . . . Whilst, however, the question of salt poisoning demands exact study, the actual records are sufficient to establish its existence as a matter of practical fact."

The object of the present note is to place on record an outbreak of salt poisoning among pigs and poultry presenting certain features. of interest, together with a few experiments performed in an endeavour to establish the exact rôle of the salt in such cases.

The history of the outbreak, as reported by the proprietor of the establishment, which is situated on the outskirts of London, was briefly as follows: The owner was in the habit of feeding considerable quantities of floor sweepings, purchased at a large London bakery, to his pigs and poultry, and a couple of days before the cases occurred about half a ton had been procured in this way. On the following afternoon (about 3.30 P.M.) two pailfuls of this material were moistened with water, placed in a trough, and fed to the ninety-eight fowls and thirty-three ducks which were allowed to run in the farmyard. At the same time thirty-four pigs of various. ages, including three breeding sows, were also fed with the moistened sweepings.

The above animals had often partaken of sweepings obtained from the same bakery. In addition, forty-two fowls were kept cooped up and specially fed for laying purposes, and these were fed with sweepings for the first time on this occasion. All the animals were stated to have eaten the food, but a little was left behind in the troughs uneaten.

Early next morning on first visiting the animals the owner discovered that a very considerable mortality had taken place, and a 
good many further deaths occurred within the course of the next twenty-four hours. Of the fowls allowed to run in the farmyard twenty-three were found dead in the early morning, and twenty more died within the next twenty-four hours. Twelve ducks were also found dead in the morning, and a couple more died during the day. In the case of the pigs four were found dead in the morning, two died during the course of the first day, and three more during the second day. Of the hens cooped up, ten were found dead in the morning, and six more died within the next thirty hours. The deaths which occurred were particularly among the youngest animals, and those in best condition. All the ducks had been reared during the season. All animals that showed symptoms succumbed later.

The symptoms exhibited by the animals which succumbed, but survived during the day after feeding with the sweepings, were intense thirst, frothing at the mouth, fœetid diarrhœa (especially in the poultry), and peculiar nervous disorders. In their anxiety to obtain water the affected fowls were stated to plunge into water like ducks. The poultry held their heads well back, as if attacked with some brain trouble, and the affected pigs circled continuously round and round and stumbled against objects, as if blind, until they became exhausted. Later the animals became affected with severe depression, and lay down as if paralysed just before death.

On the day after the occurrence of the above fatalities the owner brought for examination the carcase of one of the ducks and one of the fowls, together with about a couple of pounds of the sweepings which he suspected of having given rise to the trouble. No noteworthy lesion was observed in the duck and fowl, which showed signs of distinct post-mortem decomposition. A chemical analysis of the crop contents and sample of suspected food was made by Dr I ander, with the following results. The sweepings were of a very dirty character, containing among other things broken bits of ginger beer bottles, pieces of string and sacking, etc., together with a very large number of coarse brittle masses, up to the size of a walnut, which could be easily broken up between finger and thumb, and then seen to be composed of a white crystalline powder, readily recognised by the naked eye and by taste as common salt, almost in a state of purity. Chemical analysis of a mixed sample showed that the sweepings contained 22 per cent. by weight of sodium chloride.

Analysis of the crop contents of the fowl disclosed the presence of 7 per cent. of sodium chloride, and of 175 per cent. in the case of the duck.

Experimental.-An attempt was first made to ascertain the toxic effects of feeding with the sweepings, and with this end in view two healthy young hens were purchased, placed in separate cages, and kept without food for twenty-four hours. One bird had then placed in its trough one-quarter pound of dry sweepings, and the other the same quantity soaked with water. A supply of clean water was also left in the cages. None of the meal was eaten for two days, although the fowls in the meantime showed signs of great hunger. Difficulty in inducing single animals to partake of food material containing large proportions of salt had previously been noted by Lander in the course of feeding experiments with the pig; the "3-oz. daily doses were not eaten readily." 
The above two hens were then placed together in the same cage, and Ioo grammes of the dry meal were left in one trough, and about a pint of clean water in another. The meal was then eaten by both birds but with great caution, several mouthfuls of water being swallowed between successive mouthfuls of meal. All the sweepings were cleared up by the following morning, and the water had all been drunk, but the fowls showed no symptoms of ill-health.

On the following day 200 grammes of the dry meal were placed in the trough, but no water was left in the cage. None of the meal had been touched by the following morning.

Four days later one of the above fowls was given a full feed of oats, and in the evening 20 grammes of common salt dissolved in $70 \mathrm{cc}$. of water were injected slowly into the crop, which was well massaged to ensure mixing of the solution with the crop contents. The fowl was found dead the following morning, and death appeared to have taken place some hours previously. No naked-eye lesion was discoverable on post-mortem examination. The weight of the fowl was $I^{\prime} 25$ kilogramme, and the rapidly fatal results were therefore obtained by the administration of 16 grammes of salt per kilo. body weight. The percentage of sodium chloride discoverable in the crop contents after death by chemical analysis was nearly three and a half ( 6.125 grammes salt in 175 grammes).

A further series of experiments carried out in order to ascertain the minimum toxic dose was performed on pigeons. Three pigeons were injected into the full crop with solutions corresponding respectively, with $\cdot 625, \mathrm{I} \cdot 25$, and $2 \cdot 5$ grammes per kilo. body weight. Slight symptoms of depression were observed in the birds given the two higher doses for an hour or two after the injection, but otherwise no ill-effects were produced.

Five days later ( 6 P.M.) the same three pigeons were injected into the crop with increased doses of salt solution, viz., $2.5,3.33$, and 4.5 grammes per kilo. body weight. The pigeon given the highest dose died eighteen hours afterwards, and the one given the medium-sized dose twenty-three hours after the injection. The bird given the smallest dose showed no apparent symptoms. The other two became affected with great depression shortly after the injection, and this weakness became more and more marked until death set in. On post-mortem examination there were no lesions discoverable except acute congestion of the mucous membrane of the osophagus between the crop and the proventriculus. Chemical analysis of the crop contents of the two pigeons that succumbed disclosed the following amounts of unabsorbed sodium chloride: Highest dose pigeon, 73 per cent. ('073 grammes in Io grammes contents); medium dose pigeon, 76 per cent. ( 0877 grammes in I I' 5 grammes contents).

The percentage of sodium chloride in the crop contents of the above pigeons had thus in the interval between the injection and death fallen to that of physiological saline solution, and therefore chemical analysis of the crop contents after death in these cases would not have furnished evidence of the presence of salt poisoning. This is a very important fact in view of the above statement, quoted from Lander, with regard to doubts cast on many cases of alleged salt poisoning in pigs. 
As regards earlier records of salt poisoning in poultry the following summary of some observations made by Suffran ${ }^{1}$ (I9IO) are quoted from Lander. "Suffran describes a case in which thirteen out of fifteen fowls died after eating a salted potato mash, the symptoms setting in in twelve hours. The birds fell from their perches, showed signs of great thirst and weakness, and there was a viscous discharge from the beak. Experimental poisoning of fowls by the same author showed the dose to be 4 grammes per kilo. body weight by the injection of salt solution into the crop, and the symptoms observed appeared to show a special action on the muscles, illustrated by progressive difficulty in walking, with eventual inability to stand. But there was no true paralysis, because the muscles still exhibited reflex action. Death was attributed to asphyxia, due to loss of power of the respiratory muscles. ... Salt formed 14 per cent. of the crop contents."

Dealing with the percentages of unabsorbed salt recorded by various authors in the stomach contents in cases of salt poisoning, Lander further observes: "These proportions are very high, and they show that the chemical diagnosis of salt poisoning is a matter presenting little difficulty, even allowing for the fact that sodium chloride is a normal constituent of the body fluids." In view of the results obtained on analysis of the crop contents of the pigeons, this statement appears to require some modification.

The special interest of the minimum dose experiments resides in the fact that we are concerned with poisoning by a normal body component. In all cases of poisoning the unabsorbed residue of a minimum dose must necessarily be very small. If it is a poison foreign to the organism, its detection after minimum dosage points to the cause of death, but if, as with salt, it is natural to the organism its discovery does not diagnose poisoning.

\section{A CASE OF GLANDERS IN THE HUMAN SUBJECT.}

(EXPERIMENTAL INOCULATION IN THE HORSE AND MULE, AND A COMPARISON OF THE BLOOD IMMUNITY REACTIONS.)

By Leonard S. Dudgeon, C.M.G., F.R.C.P. (Lond.), Colonel A.M.S., Consulting Bacteriologist, British Salonika Force; S. L. Symonds, B.V.Sc., Major A.V.C., O.C. Veterinary Hospital, British Salonika Force; and A. Wilkin, B.C. (Cantab.), Captain R.A.M.C., Bacteriologist to the Central Laboratory, British Salonika Force.

History:-The patient was a Spanish Jew who lived in Salonika. He kept a coffee shop, which was also used as an immoral house, while his wife was a prostitute. He stated definitely that he had not at any time worked among horses or employed horse labour.

$\mathrm{He}$ had been ill for four months. The first abscess presented over the lower end of the right tibia, and was soon followed by many more abscesses. Every abscess, with one exception, has occurred on the legs from the knees downwards. At the commence-

1 Suffran : "Journal Comparative Pathology and Therapeutics," 1910, p. 71. 